\title{
EXPERIÊNCIA DIDÁTICA APLICADA AO ENSINO DE ROBÓTICA PARA ENGENHARIA DE CONTROLE E AUTOMAÇÃO DO IFSP
}

DIDACTIC EXPERIENCE APPLIED TO THE TEACHING OF ROBOTICS FOR CONTROL AND AUTOMATION ENGINEERING OF IFSP

Caio Igor Gonçalves Chinelato ${ }^{1}$

DOI: 10.37702/REE2236-0158.v39p123-136.2020

\begin{abstract}
RESUMO
Este trabalho apresenta uma experiência didática aplicada ao ensino de robótica para Engenharia de Controle e Automação do Instituto Federal de São Paulo (IFSP) - campus São Paulo. O objetivo foi o de que os alunos pudessem compreender conceitos fundamentais de manipulação robótica e robótica móvel através da integração entre teoria e prática. Para isto, foram realizadas experimentações práticas com um manipulador robótico e simulações computacionais com um robô móvel. Inicialmente, foram analisadas as características estruturais, mecânicas, elétricas e os recursos do manipulador robótico e do robô móvel. Posteriormente, foi realizado o estudo dos programas e comandos necessários para a programação dos robôs. Como resultado do trabalho são mostradas aplicações práticas e simulações computacionais desenvolvidas pelos alunos. Após a análise dos resultados, pôde-se perceber que a experiência didática proposta foi bastante eficaz no sentido de auxiliar os alunos na assimilação dos conceitos fundamentais de manipulação robótica e robótica móvel e também na integração entre teoria e prática.
\end{abstract}

Palavras-chave: ensino de robótica; manipulação robótica; robótica móvel; robôs didáticos.

\begin{abstract}
This work presents a didactic experience applied to the teaching of robotics for control and automation engineering of São Paulo Federal Institute - campus São Paulo. The objective was that the students could understand fundamental concepts of robotic manipulation and mobile robotics through practical and theory integration. For this purpose, it was realized practical experimentations with a robotic manipulator and computational simulations with a mobile robot. Initially, it was analyzed structural, mechanical and electrical characteristics and resources of robotic manipulator and mobile robot. Posteriorly, it was realized the study of necessary software and commands for robots programming. As results are shown practical applications and computational simulations developed by students. After results analysis, it can be seen that the proposed didactic experience was quite effective to help students in the assimilation of fundamental concepts of robotic manipulation and mobile robotics and theory and practical integration.
\end{abstract}

Keywords: teaching of robotics; robotic manipulation; mobile robotics; didactic robots. 


\section{INTRODUÇÃO}

Um dos principais tópicos da graduação em Engenharia de Controle e Automação é a robótica. Trata-se de um tópico cada vez mais aplicado tanto na indústria quanto na pesquisa acadêmica. Inicialmente, os alunos são expostos aos conceitos teóricos básicos e gerais de robótica, tais como história e tipos de robôs, cinemática, dinâmica e controle. Para assimilação prática desses conceitos, tipicamente, são realizadas experimentações com robôs didáticos e simulações computacionais. São frequentemente adotados manipuladores robóticos didáticos e, mais recentemente, robôs móveis didáticos. Essa integração entre teoria e prática é fundamental no aprendizado de robótica, por se tratar de uma área altamente interdisciplinar, que engloba tópicos como mecânica, eletrônica, programação de computadores, sistemas de controle e instrumentação.

Diversas experiências didáticas têm sido propostas e aplicadas ao ensino de robótica na engenharia. Muitos trabalhos apresentam o uso didático de manipuladores robóticos. Em Stankovski et al. (2010), é proposto o uso de um manipulador robótico didático para Engenharia Mecatrônica com o objetivo de executar tarefas industriais - como transporte de materiais - e de integração de diversos conceitos fundamentais da Engenharia Mecatrônica, como eletropneumática, sensores, atuadores, controladores lógicos programáveis (CLP) e sistemas supervisórios. Em Coutinho et al. (2012), também é analisada a aplicação didática de um manipulador robótico para engenharia, dessa vez com a finalidade de criar um sistema automático de seleção de materiais de acordo com a cor. Outros trabalhos apresentam o uso didático de robôs móveis. Em Garcia et al. (2017), é proposta a construção de um robô móvel de baixo custo para aplicação em disciplinas de engenharia. Em Demetriou (2011), são mostradas diversas plataformas didáticas para ensino e pesquisa com robôs móveis. Alguns trabalhos demonstram a experiência da aplicação de robótica educacional para o ensino de lógica de programação para diversos cursos de engenharia (GUIMARÃES; MARTINS;
ARRUDA, 2018; RIBEIRO; MARTINS; BERNARDINI, 2011). Em De França et al. (2016), é mostrada a experiência didática da utilização da robótica educacional nas disciplinas introdutórias do curso de Engenharia Elétrica com o objetivo de motivar os alunos e reduzir os índices de evasão no curso. Em Malmonge et al. (2013), é proposta a utilização de kits de robótica educacional com a finalidade de mostrar a interdisciplinaridade na engenharia e Pereira et al. (2013) apresentam a construção de robôs móveis de baixo custo com o objetivo de agilizar a aprendizagem e, por meio deles, de se aplicar conceitos de robótica.

Este trabalho apresenta uma experiência didática aplicada ao ensino de robótica para Engenharia de Controle e Automação do Instituto Federal de São Paulo (IFSP) - campus São Paulo. O objetivo foi o de que os alunos pudessem compreender conceitos fundamentais de manipulação robótica e robótica móvel através da integração entre teoria e prática. Para isso, foram realizadas experimentações práticas com um manipulador robótico e simulações computacionais com um robô móvel. Como resultado deste trabalho são mostradas aplicações práticas e simulações computacionais desenvolvidas pelos alunos.

\section{CONCEITOS FUNDAMENTAIS DA ROBÓTICA}

Nesta seção serão apresentados os conceitos fundamentais relacionados à manipulação robótica e à robótica móvel conceitos esses que foram apresentados aos alunos.

\section{Manipulação robótica}

Os manipuladores robóticos estão entre os robôs mais utilizados tanto na indústria quanto em laboratórios de pesquisa. Eles são constituídos de corpos rígidos denominados elos ou links, tipicamente feitos de um material resistente $\mathrm{e}$ interligados por juntas que possibilitam o movimento relativo entre os elos (SPONG; HUTCHINSON; VIDYASAR, 2005). Normalmente, os manipuladores estão montados sobre uma base fixa, na qual se 
encontram o primeiro elo e a primeira junta. $\mathrm{O}$ ponto extremo do último elo é conhecido como punho, onde está fixado o terminal efetuador, que opera sobre o objeto manipulado (LEWIS; DAWSON; ABDALLAH, 2004). O manipulador realiza uma tarefa que é previamente programada com o auxílio de um programa de controle.

Entre os conceitos básicos dos manipuladores robóticos estão as variáveis características ou coordenadas generalizadas, que permitem representar o movimento de um elo em relação ao anterior. Em juntas rotacionais, as variáveis características são ângulos de rotação; em juntas prismáticas, são distâncias de translação (SPONG; HUTCHINSON; VIDYASAR, 2005). O número total de juntas do manipulador é denominado graus de liberdade. Um manipulador robótico também é caracterizado pelo espaço de trabalho, que se refere ao volume total em que ele pode posicionar o terminal efetuador (CRAIG, 2017).

A análise e projeto de um manipulador robótico envolve o estudo dos seguintes tópicos: cinemática direta e inversa; matriz Jacobiana; dinâmica; planejamento de caminho; geração de trajetória; controle; e programação (SPONG; HUTCHINSON; VIDYASAR, 2005).

A cinemática estuda o movimento do robô sem considerar as forças (ou torques) que o causam. A cinemática direta determina a posição e orientação cartesiana do terminal efetuador dadas as coordenadas generalizadas e é obtida através de um procedimento sistemático descrito por Denavit e Hartenberg, em que transformações de coordenadas entre os elos do manipulador são representadas através de matrizes (CRAIG, 2017). A cinemática inversa determina o conjunto de coordenadas generalizadas possíveis que podem gerar uma determinada posição e orientação cartesiana do terminal efetuador. Trata-se de um problema mais complexo devido às não linearidades e à existência de posições com múltiplas soluções ou nenhuma solução (singularidade). A matriz Jacobiana trata das relações entre velocidades do terminal efetuador e velocidades das juntas (CRAIG, 2017).
A dinâmica descreve as relações entre forças (ou torques) e movimentos do manipulador robótico. O modelo matemático dinâmico é tipicamente obtido a partir da formulação de Euler-Lagrange ou de NewtonEuler (SPONG; HUTCHINSON; VIDYASAR, 2005).

O planejamento de caminho é a determinação de um caminho no espaço de trabalho partindo-se de uma posição inicial até uma posição final. Uma vez que se tem o caminho, são geradas as trajetórias de referência. As trajetórias geram entradas de referência para o controle de posição do manipulador. Tendo as referências, deve-se determinar as forças (ou torques) a serem aplicadas pelos atuadores das juntas de forma a satisfazer requisitos transitórios e de regime permanente (OGATA, 2011), garantindo, assim, uma execução precisa da tarefa programada. Existem aplicações em que o manipulador precisa manter uma força específica sobre uma superfície. Nesse caso, também é aplicado controle de força (LEWIS; DAWSON; ABDALLAH, 2004).

Finalmente, temos a programação do manipulador, na qual são fornecidas as coordenadas para o terminal efetuador de forma que o manipulador realize a tarefa programada.

\section{Robótica móvel}

Nos últimos anos os robôs móveis têm sido muito utilizados tanto na indústria quanto na pesquisa acadêmica. A principal vantagem de um robô móvel em relação a um manipulador robótico é a mobilidade e a flexibilidade. Existem robôs móveis terrestres movidos por rodas, denominados AGVs (Autonomous Guided Vehicle), e por pernas. Também existem robôs móveis submarinos, denominados AUVs (Autonomous Underwater Vehicle), e aéreos, como os quadricópteros. Os robôs móveis caracterizam-se por uma ampla variedade de aplicações tais como limpeza, coleta e distribuição de materiais, entretenimento, aplicações espaciais e coleta de dados ambientais (SIEGWART; NOURBAKHSH, 2004). 
O estudo dos robôs móveis envolve conceitos muito semelhantes ao estudo de manipuladores robóticos, tais como cinemática, dinâmica, controle e programação. No entanto, devido à mobilidade, deve-se também estudar o problema da navegação (NEHMZOW, 2003). A navegação dos robôs móveis envolve os seguintes tópicos:

a) percepção: o robô deve interpretar os sinais de seus sensores a fim de extrair informações relevantes do ambiente que o cerca;

b) mapeamento e localização: o robô deve mapear o ambiente e determinar sua posição em relação a este ambiente;

c) cognição: o robô deve decidir como agir para atingir os seus objetivos e executar a tarefa para o qual foi programado;

d) controle do movimento: o robô deve atuar nos seus motores para realizar as trajetórias e movimentações determinadas na etapa de cognição.

O problema da navegação constitui um tópico altamente interdisciplinar, envolvendo áreas como instrumentação, programação de computadores, eletrônica e, em muitos casos, até mesmo inteligência artificial (KORTENKAMP; BONASSO; MURPHY, 1998).

\section{MATERIAIS E METODOLOGIA DIDÁTICA}

O objetivo da experiência didática mostrada neste trabalho foi de que os alunos da Engenharia de Controle e Automação do IFSP pudessem compreender conceitos fundamentais de manipulação robótica e robótica móvel através da integração entre teoria e prática. A metodologia didática foi guiada de forma que esses objetivos fossem atingidos.

Inicialmente, os alunos cursam uma disciplina de robótica teórica na qual estudam os conceitos fundamentais de manipulação robótica e robótica móvel. Posteriormente, cursam uma disciplina de robótica prática, com a finalidade de melhor assimilação desses conceitos fundamentais e de integração entre a teoria e a prática. Nessa disciplina, foram realizadas experimentações práticas com um manipulador robótico didático e simulações computacionais com um robô móvel didático.

Muitos trabalhos apresentados na literatura sobre manipuladores robóticos aplicados ao ensino de engenharia tratam de manipuladores de menor porte. $\mathrm{O}$ manipulador adotado foi o ARISTO, fabricado pela empresa MTAB 2. Trata-se de um manipulador de maior porte e mais compatível com os manipuladores encontrados em ambientes industriais. $\mathrm{O}$ manipulador é programado por meio do software M-ROBOT.

Até alguns anos atrás, as disciplinas de robótica para graduação focavam no ensino de manipuladores robóticos. No entanto, com a crescente utilização de robôs móveis, tanto na indústria quanto na pesquisa acadêmica, é muito importante que sejam ensinados tópicos teóricos e práticos relacionados a estes. $\mathrm{Na}$ disciplina analisada neste trabalho, foi realizado o estudo do robô móvel Robotino®, fabricado pela empresa Festo3. A empresa Festo disponibiliza gratuitamente o software de programação (Robotino® View) e o software de simulação do robô móvel (Robotino ${ }^{\circledR}$ Sim); portanto, foram realizados programas e obtidos resultados no ambiente de simulação.

Inicialmente, foram analisadas as características estruturais, mecânicas, elétricas e os recursos do manipulador robótico e do robô móvel. Tais características são descritas detalhadamente nos manuais dos fabricantes dos robôs. Posteriormente, foram realizados o estudo e o treinamento dos programas e comandos necessários para a programação dos robôs. Finalmente, foram propostas aos alunos tarefas a serem programadas e executadas pelo manipulador robótico e pelo robô móvel.

\section{Manipulador robótico ARISTO}

O manipulador robótico didático adotado foi o ARISTO, fabricado pela empresa MTAB e mostrado na Figura 1. O manipulador robótico possui seis graus de liberdade com juntas rotacionais. As juntas são controladas 
por servomotores e o terminal efetuador é uma garra com acionamento pneumático. $\mathrm{Na}$ figura 1 são especificados os seis graus de liberdade. Temos três graus de liberdade de posição, representados pela base (eixo A1), ombro (eixo
A2) e cotovelo (eixo A3) e três graus de liberdade de orientação, representados pelo punho (eixo A4), arfagem (eixo A5) e rolamento (eixo A6).

\section{Figura 1 - Manipulador robótico ARISTO}

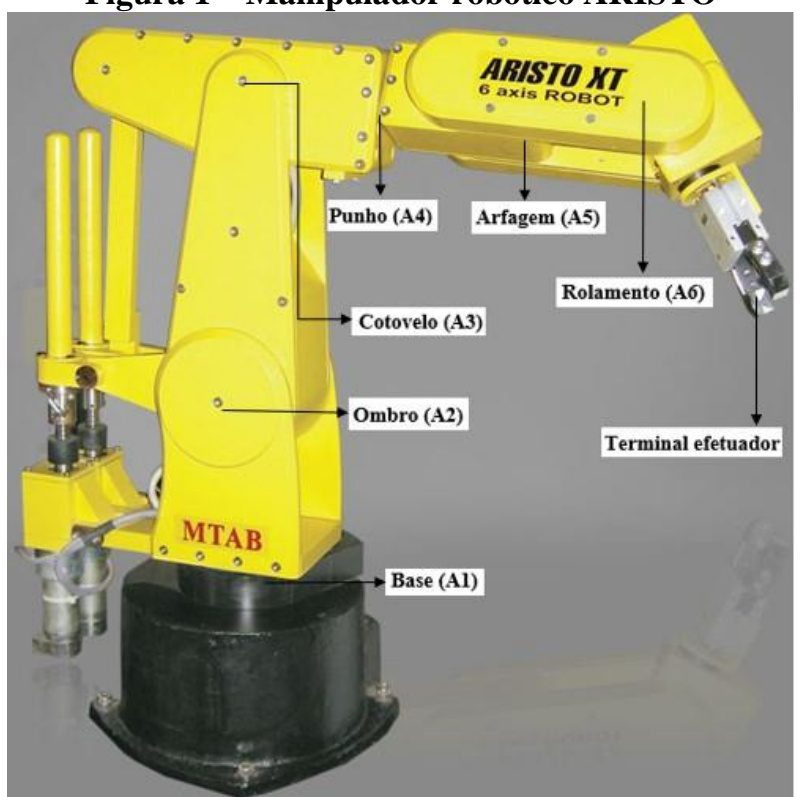

Fonte: adaptada do Website da MTAB.

Um diagrama de conexão do manipulador é mostrado na Figura 2. O manipulador possui seu próprio controlador (MTAB 8860) e é programado através do software M-ROBOT, que fica instalado em um computador que, juntamente com o controlador, comanda os servomotores para movimentação dos graus de liberdade. A comunicação entre o software M-ROBOT e o manipulador é feita através de um cabo Ethernet.

Figura 2 - Diagrama de conexão entre o manipulador ARISTO e o software de programação M-ROBOT

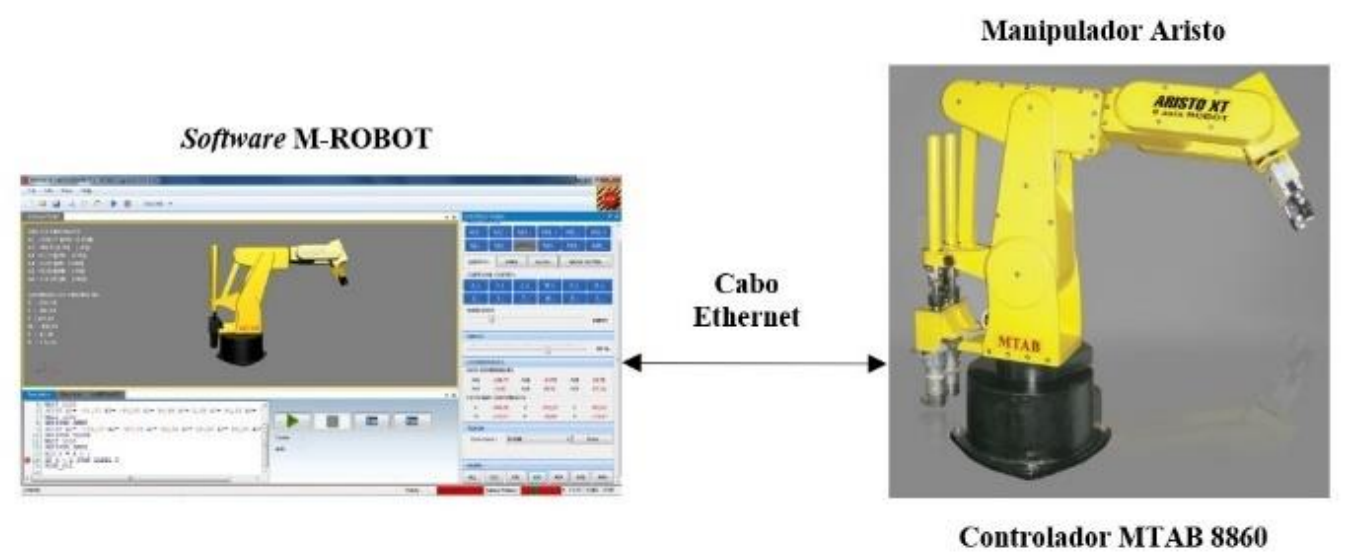

Fonte: elaborada pelo autor. 
O controlador MTAB 8860 possui diversos recursos como memória Flash, FPGA, controle em tempo real multitarefa, interfaces de potência para motor de passo e servomotor, interface USB, estrutura robusta, antiinterferência, isolamento, linhas de comunicação serial RS232, interface com protocolo CAN e entradas e saídas digitais.

$\mathrm{O}$ manipulador robótico pode ser programado no modo off-line e no modo online. No modo off-line, programas podem ser testados sem haver conexão com o manipulador, ou seja, o software M-ROBOT funciona como um simulador para que os programas sejam testados antes de serem executados. No modo on-line, o software MROBOT precisa obrigatoriamente estar conectado com o manipulador através do cabo Ethernet; portanto, somente nesse modo o programa será carregado e executado no manipulador.

Na Figura 3, são indicados os principais elementos do software M-ROBOT. O manipulador pode ser representado nos sistemas de coordenadas axiais ou globais. No sistema de coordenadas axiais, a posição final do terminal efetuador é representada em termos dos ângulos dos seis graus de liberdade (A1, A2, A3, A4, A5, A6), dados em graus. No sistema de coordenadas globais, a posição final do terminal efetuador é representada em termos das coordenadas cartesianas dos três graus de liberdade de posição (X, Y, Z) e das coordenadas cartesianas dos três graus de liberdade de orientação (W, P, R), dados em $\mathrm{mm}$. O painel de simulação demonstra graficamente a movimentação do manipulador, apresentando as coordenadas axiais e globais tanto no modo on-line quanto no modo off-line. No painel de controle são apresentados comandos para movimentar o manipulador usando coordenadas axiais ou globais, ajustes de velocidade, gravação de posições e o Home - comando muito encontrado nos manipuladores e que envia o manipulador para uma posição de referência antes de iniciar um determinado programa. $\mathrm{O}$ painel de execução apresenta uma janela de edição na qual os programas são implementados através de um código de programação específico com comandos semelhantes à linguagem $\mathrm{C}$ e código
$\mathrm{G}$ de comandos numéricos computadorizados (CNC). No painel do menu, são apresentados comandos básicos como salvar ou abrir programas e seleção do modo on-line ou offline. $\mathrm{O}$ botão de parada faz o manipulador parar imediatamente em alguma situação de emergência. Há também comandos para iniciar ou pausar o programa, executar linha a linha ou executar uma única linha.

Figura 3 - Principais elementos do software $\mathrm{M}$ ROBOT

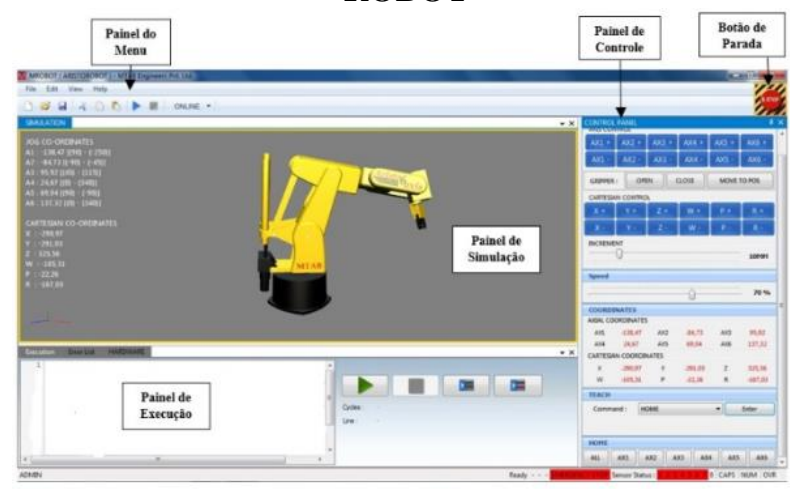

Fonte: elaborada pelo autor.

\section{Robô móvel Robotino®}

Robotino® é um robô móvel didático fabricado pela empresa Festo. O robô móvel é mostrado na Figura 4.

Figura 4 - Robô móvel Robotino®

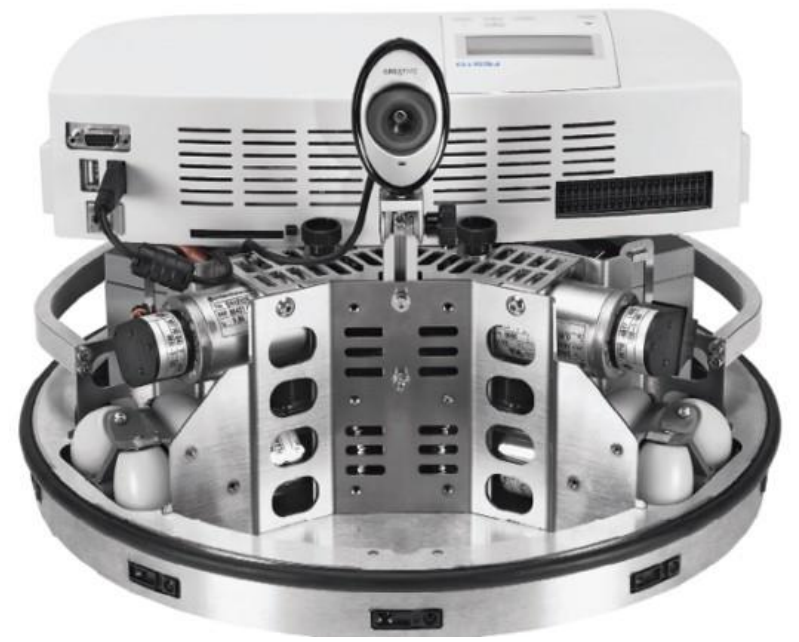

Fonte: Website da Festo.

O Robotino® é montado sob uma plataforma de aço e possui três rodas omnidirecionais independentes, espaçadas $120^{\circ}$ entre si e que possibilitam realizar movimentos em todas as direções. As unidades de acionamento das rodas omnidirecionais são 
constituídas por um motor DC, um sistema de redução por engrenagens, uma correia dentada e um encoder incremental. A alimentação é feita com duas baterias recarregáveis de $12 \mathrm{~V}$.

O robô móvel possui um controlador constituído por um processador PC104, que opera a $300 \mathrm{MHz}$ e com sistema operacional Linux. Possui uma memória SDRAM de 128 MB e um cartão de memória Flash de $256 \mathrm{MB}$, comunicação com wireless LAN e interfaces para Ethernet, VGA, USB, RS232, além de interfaces de entrada/saída, nas quais pode-se conectar adicionalmente oito entradas analógicas (0 a $10 \mathrm{~V})$, oito entradas digitais, oito saídas digitais e duas saídas a relé. $\mathrm{O}$ controlador também possui uma interface homem-máquina (IHM), em que o usuário pode inicializar o robô, selecionar o idioma, configurar a rede e selecionar uma série de programas de demonstração que já estão gravados na memória do Robotino®.

O Robotino ${ }^{\circledR}$ possui diversos sensores para interpretar informações do ambiente e realizar a navegação com eficiência. $\mathrm{O}$ robô possui nove sensores infravermelhos para medidas de distância, que são montados na estrutura do robô e espaçados $40^{\circ}$ entre si, encoder incremental juntamente com controle PID nas unidades de acionamento para que o controle de posição e de velocidade possa ser realizado com precisão, sensor anti-colisão (bumper) montado em toda a circunferência da estrutura do robô e uma câmera com interface USB e facilmente ajustável ao robô. Outros sensores, tais como óticos e indutivos, podem ser facilmente adicionados ao robô móvel usando-se as interfaces de entrada/saída do controlador.

O Robotino® é programado pelo software Robotino® View instalado em um computador e se comunica com o robô usando wireless LAN. O software Robotino ${ }^{\circledR}$ View envia comandos para as unidades de acionamento de acordo com o programa implementado e supervisiona e avalia os valores dos sensores. A programação é realizada através da interligação lógica de blocos funcionais. Cada tipo de bloco funcional tem uma aplicação específica e eles são classificados em blocos lógicos; matemáticos; análise vetorial; processamento de imagem; geradores; filtros; hardware do
Robotino®; navegação; dispositivos de entrada; extração de dados; controle de sequência; e organização de programas. É importante destacar que o Robotino ${ }^{\circledR}$ possui APIs (Application Programming Interface) para linguagens de programação como $\mathrm{C}, \mathrm{C}++$, C\#, Java, além de Matlab e LabView.

Na Figura 5, é mostrada uma aplicação desenvolvida com Robotino® View. Na parte superior do software estão os comandos para abrir, fechar e salvar programas; para executar, pausar ou encerrar a execução do programa. $\mathrm{Na}$ parte direita do software estão os blocos funcionais. Na parte inferior do software são mostradas as interfaces de cada bloco funcional e na parte central está a aplicação implementada com os blocos funcionais.

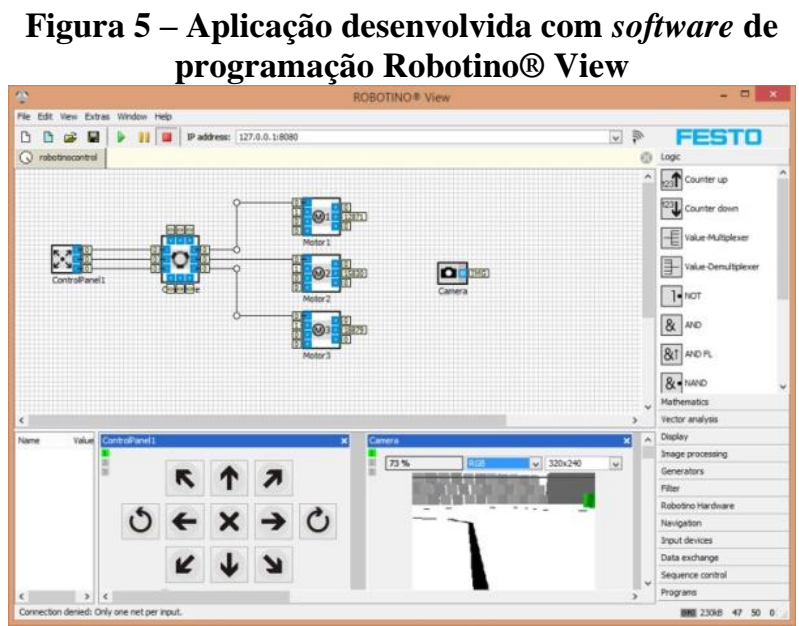

Fonte: elaborada pelo autor.

Além do software Robotino ${ }^{\circledR}$ View, há também o software Robotino® Sim, que apresenta um ambiente de simulação com o robô móvel, obstáculos, objetos coloridos e marcas pretas no chão. Com isso, os programas podem ser testados no ambiente de simulação (Figura 6). Os dois softwares podem ser executados simultaneamente; portanto, a execução dos programas desenvolvidos no Robotino® View pode ser vista no Robotino® Sim. Na experiência didática proposta neste trabalho, os resultados dos programas desenvolvidos pelos alunos foram obtidos no ambiente de simulação do Robotino ${ }^{\circledR}$ Sim. 
Figura 6 - Ambiente de simulação do software Robotino ${ }^{\circledR}$ Sim

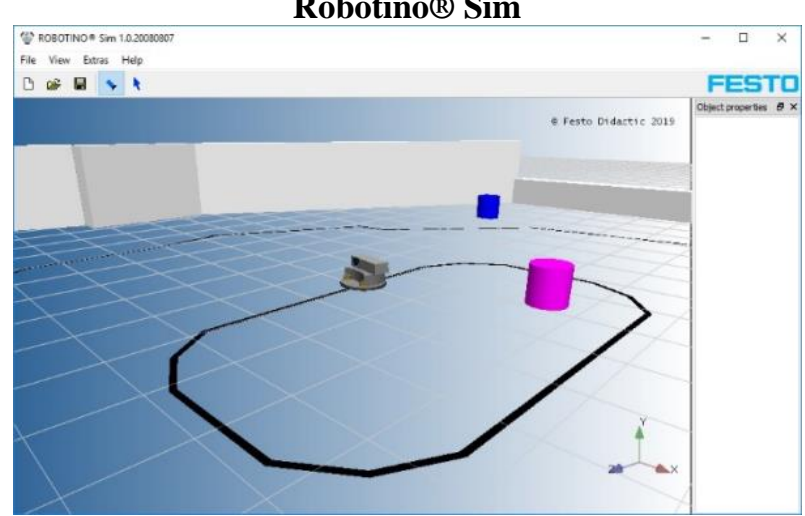

Fonte: elaborada pelo autor.

\section{RESULTADOS E DISCUSSÕES}

Nesta seção serão mostrados alguns resultados obtidos pelos alunos nas experimentações práticas com o manipulador robótico ARISTO e simulações computacionais com o robô móvel Robotino®.

\section{Manipulador robótico}

Após análise e estudo das características e da programação do manipulador ARISTO, foi proposta uma tarefa aos alunos. A tarefa proposta foi gravar algumas posições no espaço de trabalho e posteriormente executar uma trajetória passando por essas posições uma quantidade definida de vezes, simulando a programação de processos industriais típicos, tais como transporte de peças ou carga e descarga de materiais.

Inicialmente, os seis eixos do manipulador são enviados para a posição de referência (Home). O manipulador se desloca até a posição 1, fecha o terminal efetuador pneumático, representando a pegada da carga, e aguarda alguns segundos. Posteriormente, o manipulador se desloca até a posição 2 , abre o terminal efetuador pneumático, representando a soltura da carga, e novamente aguarda alguns segundos. O processo é repetido uma quantidade definida de vezes, representando o transporte de várias cargas. As posições 1 e 2 foram gravadas antes da implementação da programação.

Nas figuras a seguir são mostrados alguns resultados obtidos pelos alunos. Nas Figuras 7, 8 e 9 são exibidas as posições de referência
(Home), posição 1 e posição 2, respectivamente. As coordenadas das posições podem ser vistas no painel de simulação do software M-ROBOT, como mostrado na Figura 10.

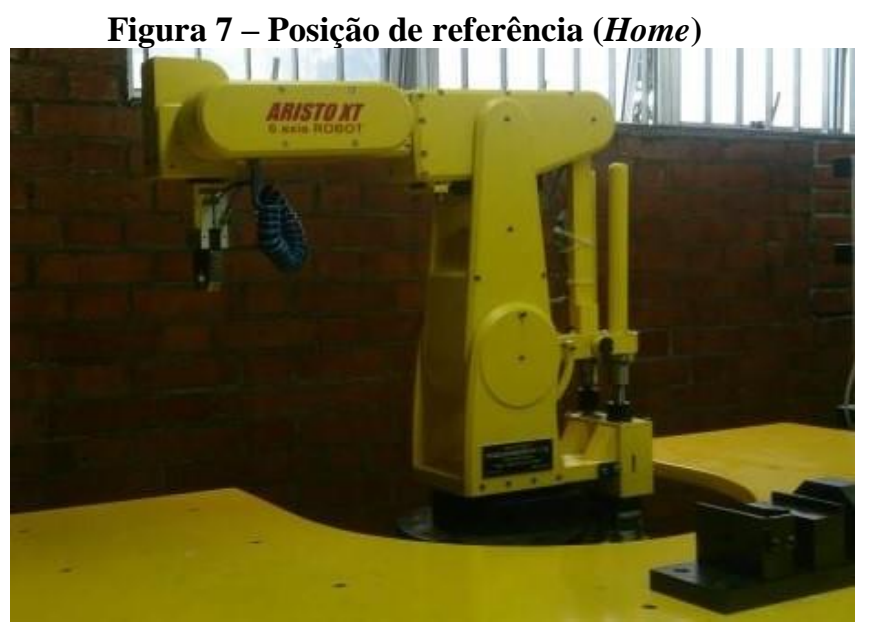

Fonte: acervo do autor.

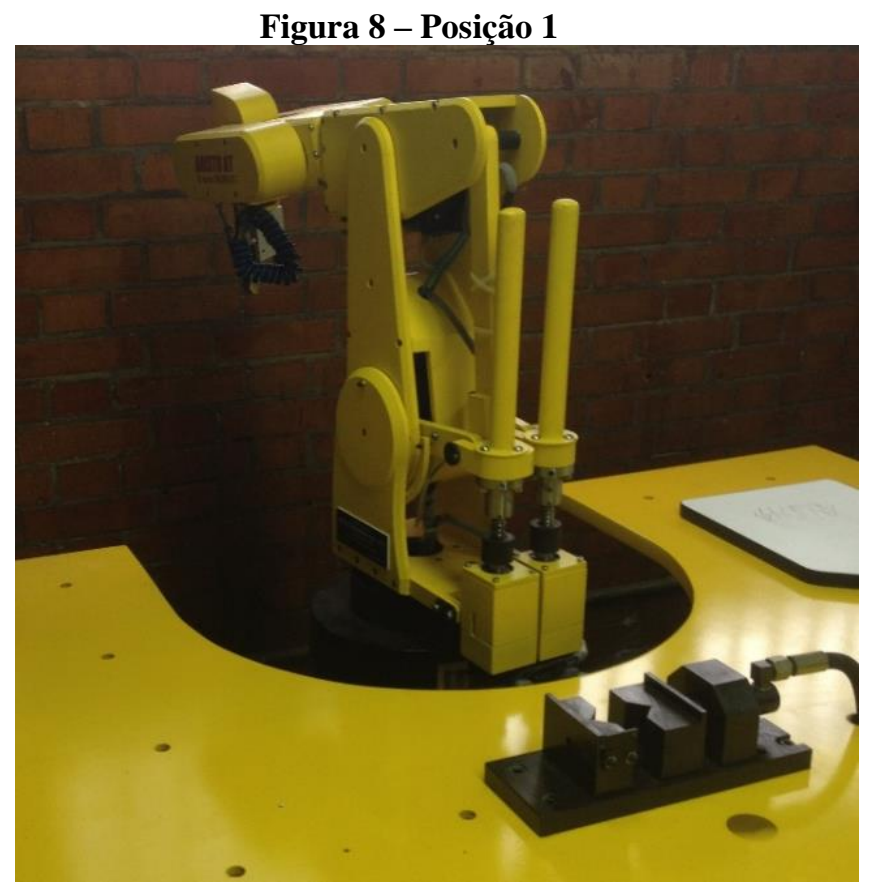

Fonte: acervo do autor. 
Figura 9 - Posição 2

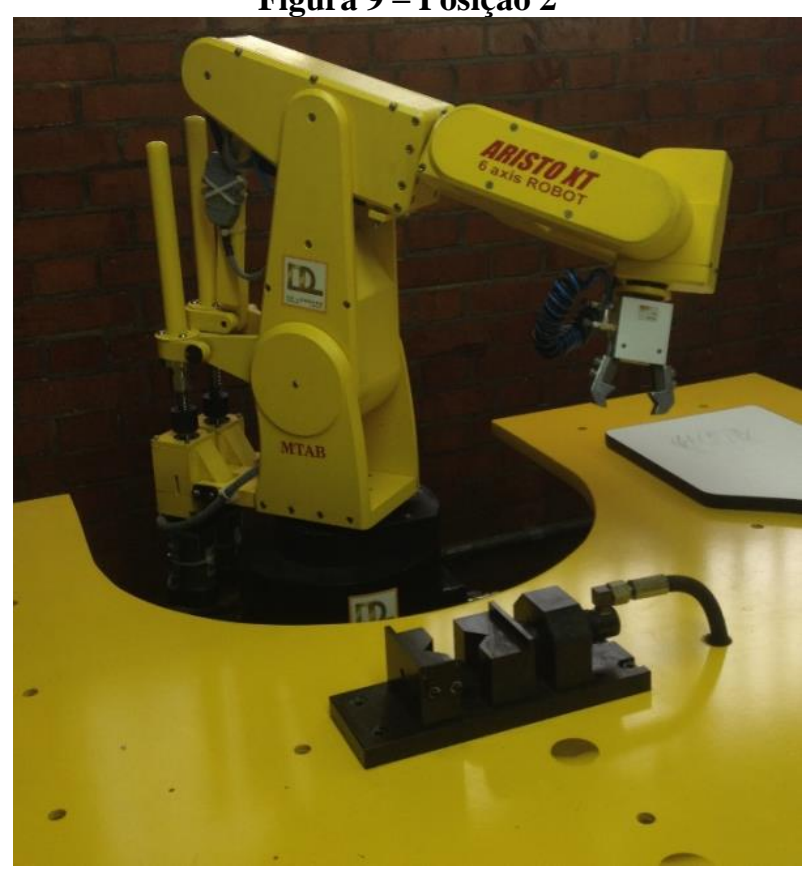

Fonte: acervo do autor.

Figura 10 - Coordenadas das posições mostradas no painel de simulação do software M-ROBOT

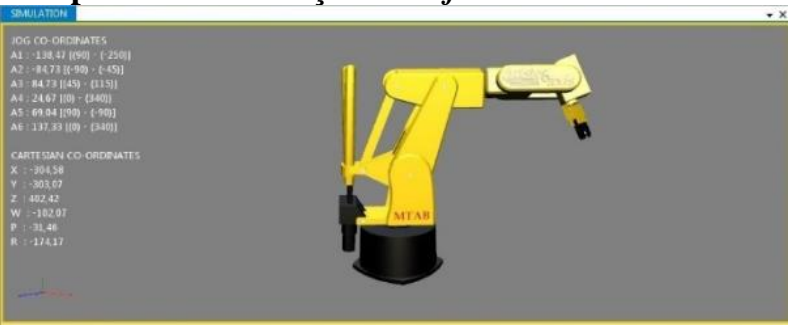

Fonte: elaborada pelo autor.

Foi proposto que os alunos realizassem diversas modificações nos programas, tais como trajetórias com três ou mais posições gravadas, ajustes nos incrementos de posições e de velocidades do manipulador entre outras. Tais modificações foram propostas visando a uma maior familiarização dos alunos com os conceitos de programação de manipuladores robóticos. Em todos os resultados houve boa precisão e repetibilidade no posicionamento do manipulador robótico.

\section{Robô móvel}

Após a análise e estudo das características e da programação do robô móvel Robotino®, foram propostas tarefas aos alunos. Todos os programas foram desenvolvidos no Robotino ${ }^{\circledR}$ View e os resultados simulados foram obtidos no Robotino® Sim.
Como tarefa inicial, os alunos implementaram quatro programas básicos. Os programas foram os seguintes:

Programa 1: controle de movimentação do robô móvel, utilizando o bloco funcional ControlPanel no qual o usuário pode fornecer a velocidade de referência do robô e do bloco funcional Omnidrive para o cálculo das velocidades a serem desenvolvidas nos motores das rodas omnidirecionais. Além disso, mostrar a imagem da câmera do robô com seu bloco funcional correspondente;

Programa 2: acrescentar ao programa 1 o bloco funcional Odometry, para que a posição do robô seja estimada conforme ele navega no ambiente de simulação e também acrescentar os blocos funcionais PositionView e PathDriver para que a posição de referência do robô possa ser fornecida pelo usuário;

Programa 3: identificar um padrão de cor no ambiente de simulação com a câmera do robô utilizando os blocos funcionais Camera, Segmenter e Segment extractor;

Programa 4: seguir uma linha preta marcada no chão do ambiente de simulação com a câmera do robô utilizando o bloco funcional Line detector.

Como tarefa final, foi proposto que os alunos criassem um programa de navegação para ser aplicado no ambiente de simulação, em que o robô segue uma trajetória ao mesmo tempo que evita obstáculos usando seus sensores específicos e identifica objetos por cor usando sua câmera. Trata-se de um problema de mais alta complexidade e que envolve a aplicação de todos os blocos funcionais e programas tratados na tarefa inicial. Os alunos elaboraram diversas estratégias e programas para a solução da tarefa. A seguir serão mostrados alguns resultados obtidos pelos alunos.

Na Figura 11, é mostrada a navegação do robô usando o bloco funcional PositionView. Este bloco fornece uma janela gráfica 
bidimensional e uma representação do robô. Se o usuário deslocar a representação do robô nesta janela gráfica, o robô irá se deslocar proporcionalmente no ambiente de simulação.

Figura 11 - Navegação do robô usando o bloco funcional PositionView
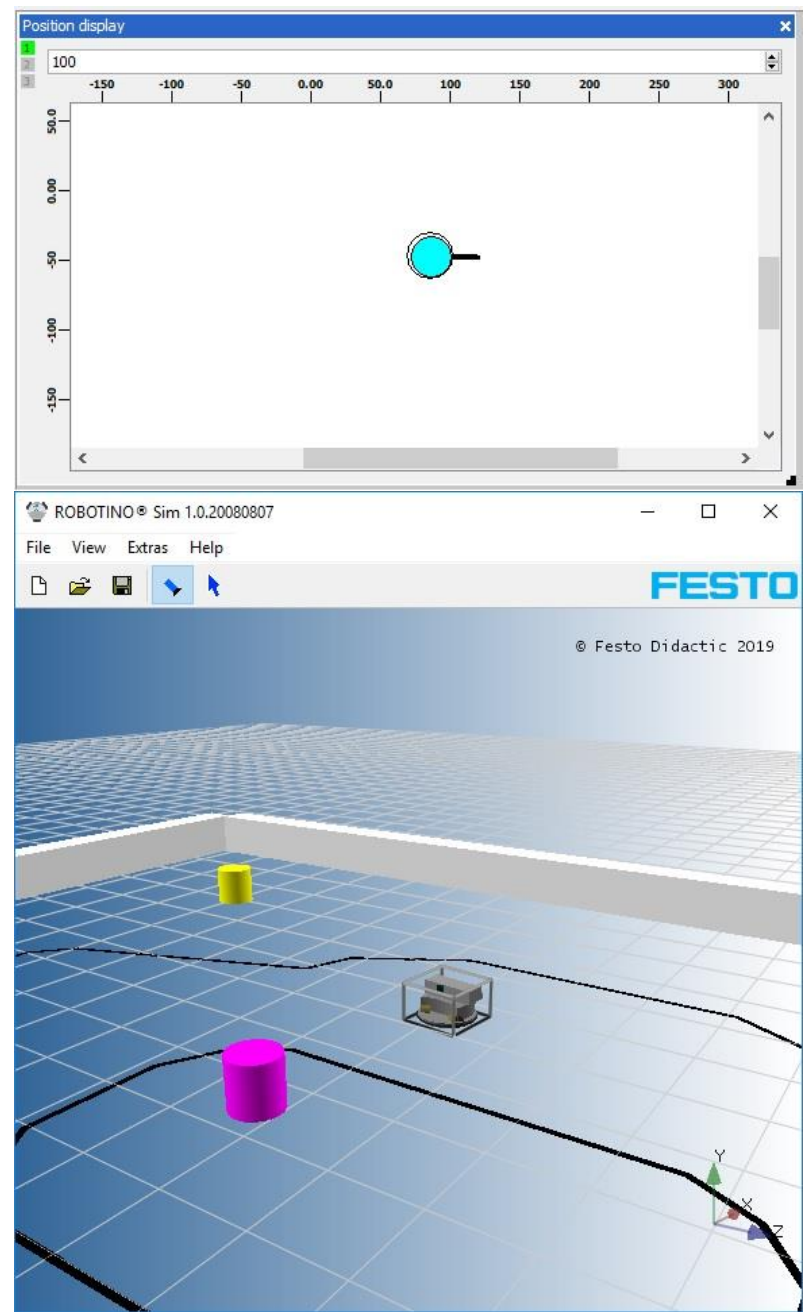

Fonte: acervo do autor.

Na Figura 12, o robô segue uma linha preta marcada no chão. O bloco funcional Line detector utiliza a imagem captada pela câmera e indica que a linha preta foi detectada através de um ponto vermelho.
Figura 12 - Robô segue uma linha preta marcada no chão

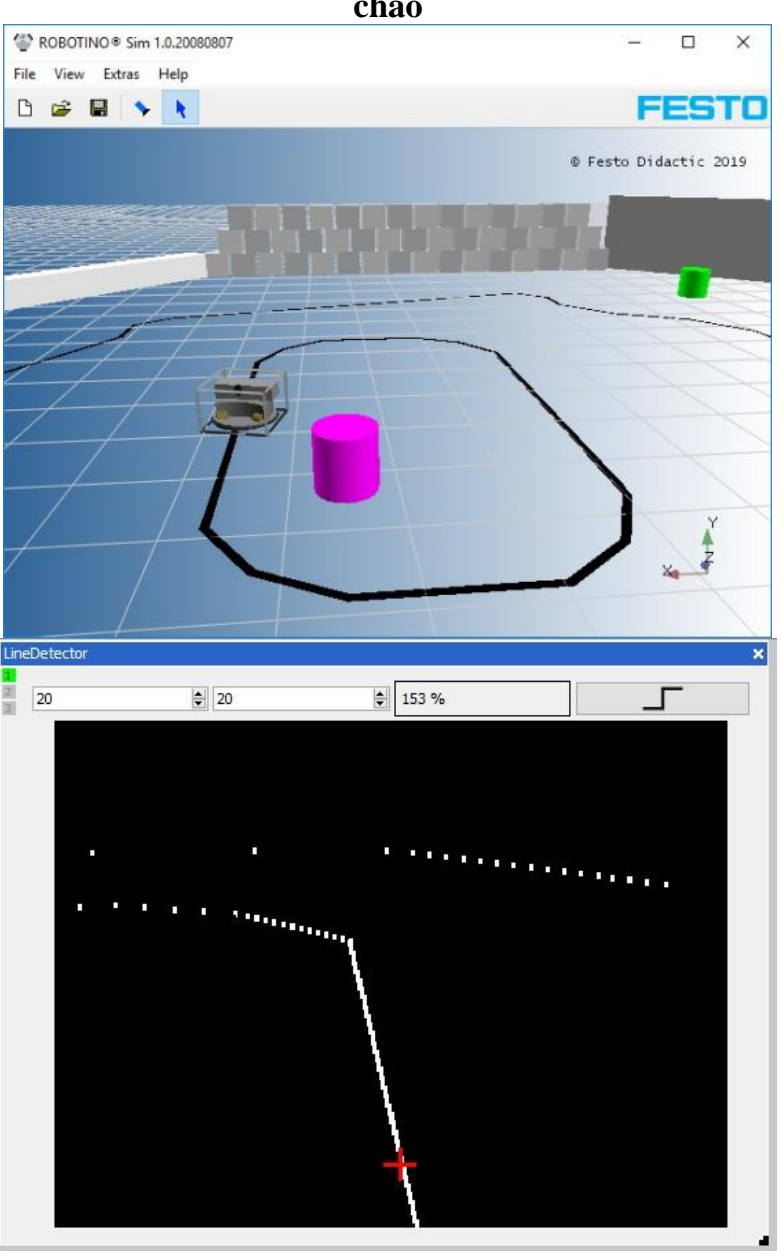

Fonte: acervo do autor.

Nas Figuras 13 e 14, são mostradas estratégias para desvio dos obstáculos. $\mathrm{Na}$ Figura 13, o robô desvia do obstáculo transladando lateralmente; na Figura 14, o robô desvia do obstáculo rotacionando. Para isto, foram utilizados os sensores infravermelhos e o sensor anti-colisão (bumper). 
Figura 13 - Desvio do obstáculo transladando lateralmente

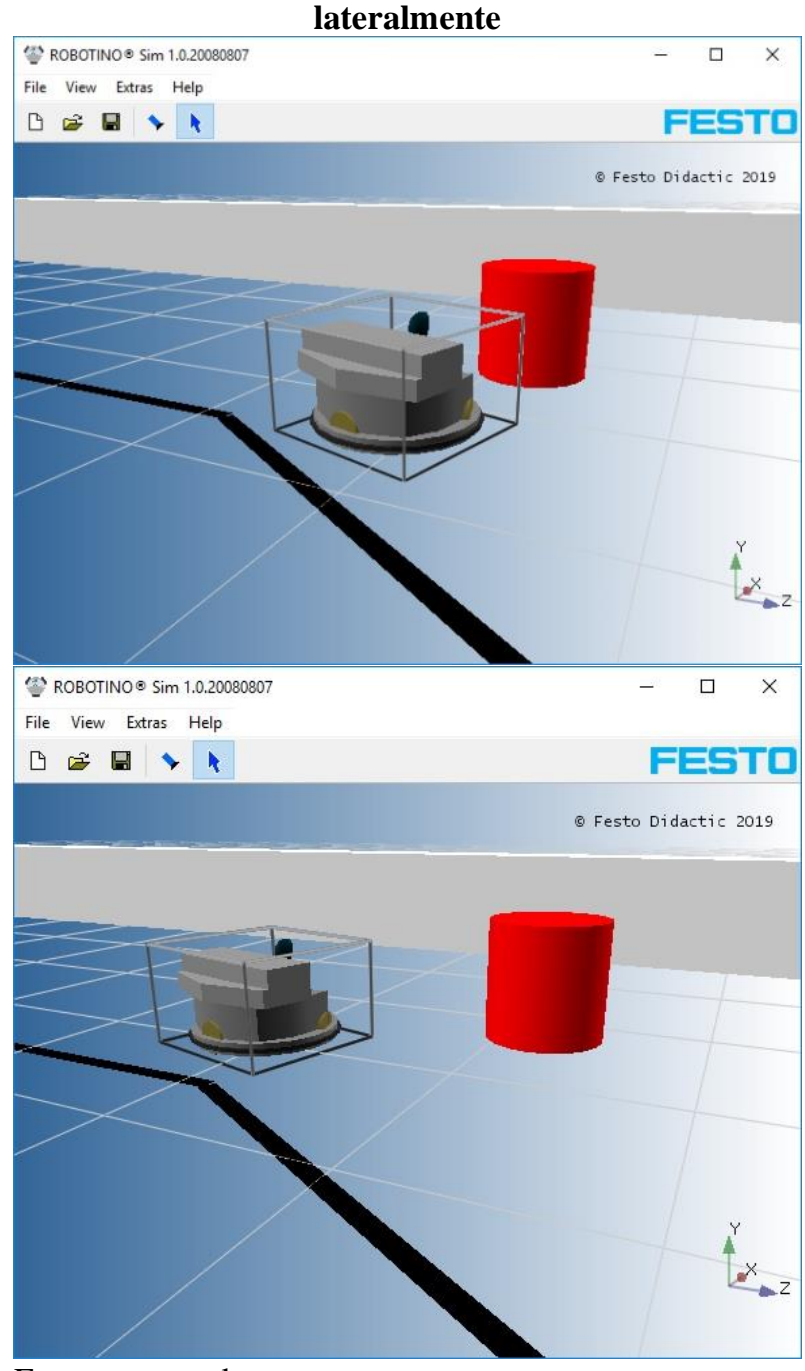

Fonte: acervo do autor.

\section{Figura 14 - Desvio do obstáculo rotacionando}

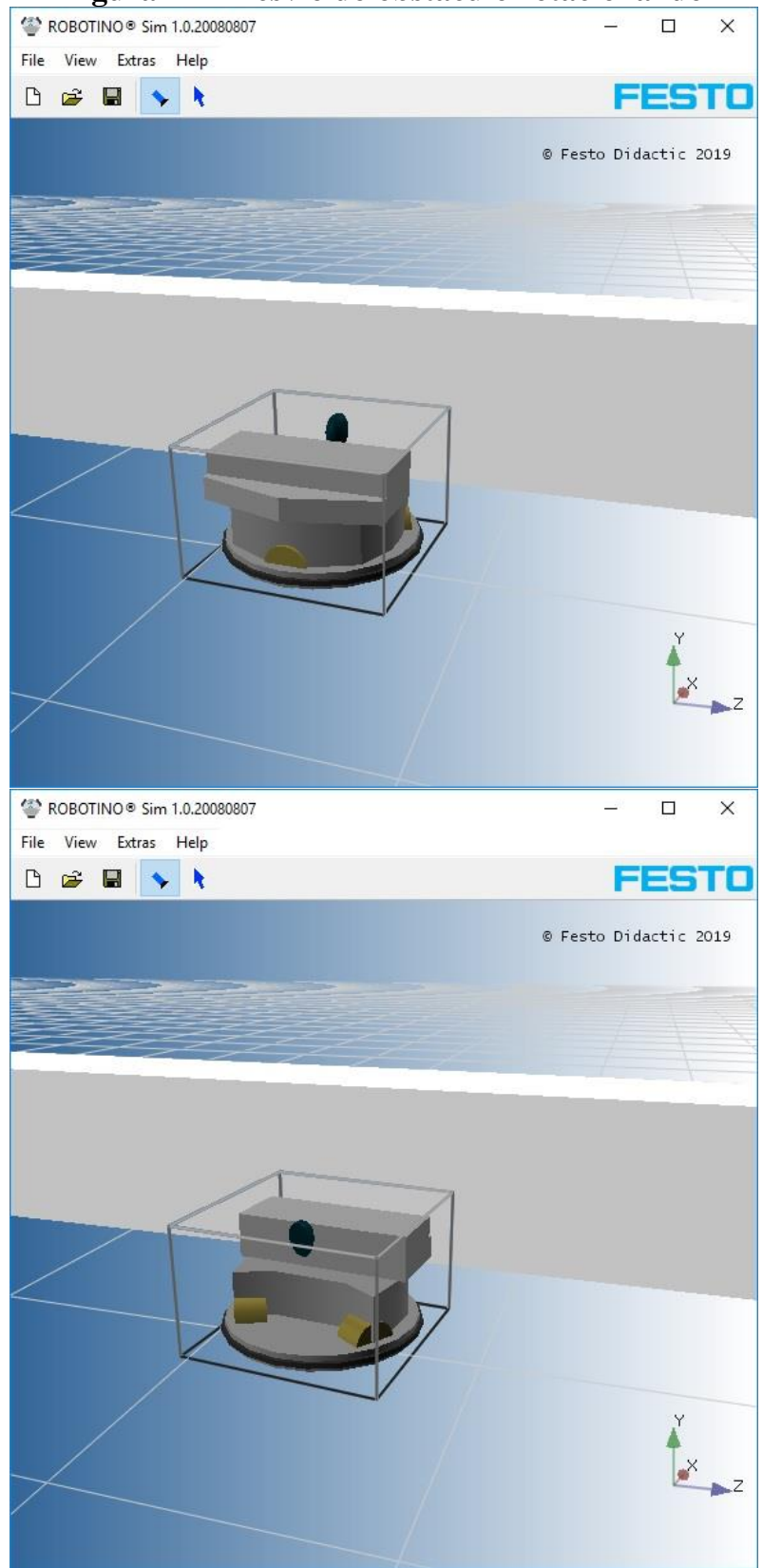

Fonte: acervo do autor. 
Na Figura 15, um objeto do ambiente de simulação é detectado pela cor. O bloco funcional Segmenter determina o padrão de cor a ser buscado e o bloco funcional Segment extractor identifica o padrão de cor encontrado com um ponto vermelho.

Figura 15 - Detecção de um objeto pela cor

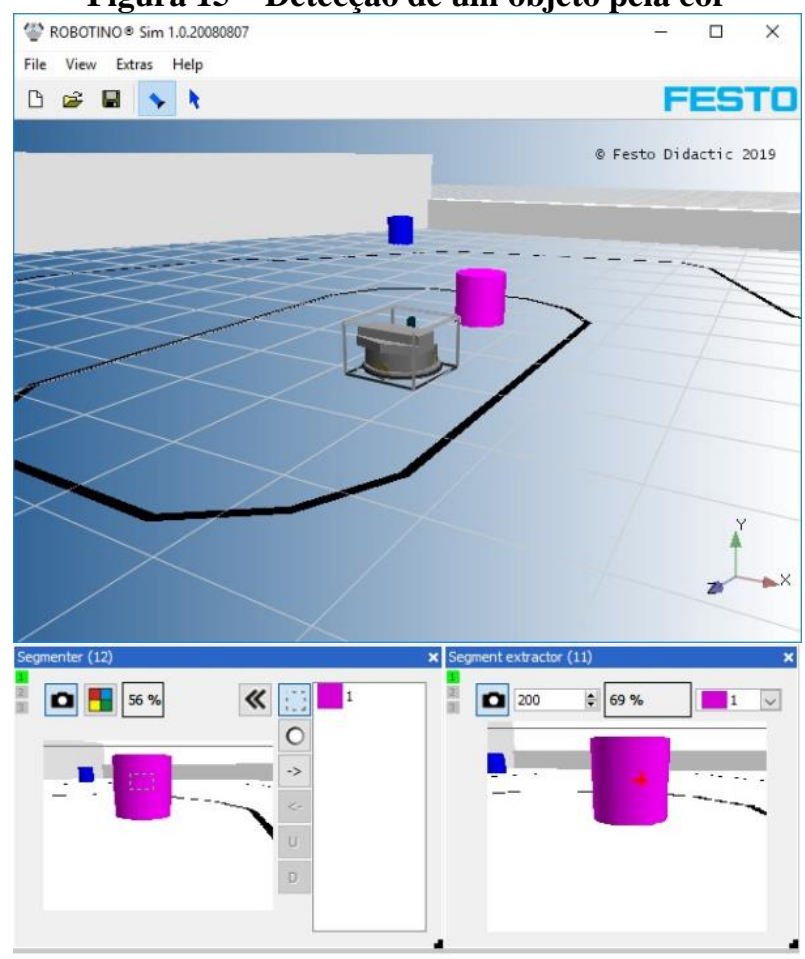

Fonte: acervo do autor.

\section{CONCLUSÕES}

Este trabalho apresenta uma experiência didática aplicada ao ensino de robótica para Engenharia de Controle e Automação do Instituto Federal de São Paulo (IFSP) - campus São Paulo. Após a realização das experimentações práticas com o manipulador robótico e as simulações computacionais com o robô móvel, pôde-se perceber que os alunos puderam compreender os conceitos fundamentais de manipulação robótica e robótica móvel através da integração entre teoria e prática.

Através da experimentação prática com o manipulador robótico, os alunos assimilaram a aplicação dos conceitos de cinemática, dinâmica, controle e programação de manipuladores. A cinemática pode ser vista nas relações de posicionamento entre os elos e juntas nas coordenadas axiais e globais do manipulador. A dinâmica foi verificada através das relações entre os torques aplicados nas juntas pelos servomotores e na movimentação do manipulador. Analisando o comportamento das posições e velocidades das juntas em regime transitório e em regime permanente, o controle do manipulador pôde ser verificado. Finalmente, por meio do treinamento do software de programação e da realização da tarefa proposta, os alunos compreenderam como é realizada a programação de manipuladores robóticos.

Com as simulações computacionais com o robô móvel, os alunos puderam assimilar os conceitos de navegação e programação de robôs móveis. Após a realização das tarefas propostas, os alunos verificaram como as informações dos diversos sensores do robô móvel são integradas de modo que o robô possa realizar as tarefas básicas de navegação, tais como localização, mapeamento, cognição e controle de movimento. Através do treinamento do software de programação, os estudantes puderam se familiarizar com a programação de robôs móveis.

A análise das características estruturais, mecânicas, elétricas e dos recursos do manipulador robótico e do robô móvel foi um recurso didático bastante interessante, pois os alunos tiveram uma noção básica de como são realizadas a construção e a implementação de manipuladores robóticos e robôs móveis. Além da interdisciplinaridade envolvida na análise de tais características, isso pode ser considerado um complemento para disciplinas na área de elétrica, eletrônica e mecânica.

\section{REFERÊNCIAS}

COUTINHO, R. T. et al. O uso pedagógico de um manipulador robótico, utilizando o reconhecimento de cores para separação de elementos em uma esteira. Anais... Workshop de Robótica Educacional (WRE), Fortaleza, CE, 2012.

CRAIG, J. J. Introduction to robotics: mechanics and control. New York, Pearson, 2017.

DE FRANÇA, A. A. et al. Utilização da robótica educacional na disciplina de 
introdução à Engenharia Elétrica do IFPB como agente motivador para permanência no curso de Engenharia Elétrica. Anais... Mostra Nacional de Robótica (MNR), Recife, PE, 2016.

DEMETRIOU, G. A. Mobile robotics in education and research. Mobile robots currents and trends. IntechOpen, October, 2011.

FESTO. Robotino®. Disponível em: $<$ https://www.festo-didactic.com/int en/services/robotino>. Acesso em: 13 jul. 2019.

GARCIA, T. R. et al. Construção de um robô móvel para ensino das disciplinas dos cursos de engenharia. Anais... Congresso Brasileiro de Educação em Engenharia (COBENGE), Joinville, SC, 2017.

GUIMARÃES, L. J. B. L. S.; MARTINS, A. L.; ARRUDA, A. P. D. O uso de robótica educacional no ensino de lógica de programação para engenheiros de produção. Revista Principia - Divulgação científica e tecnológica do IFPB, n. 39, p. 87-93, 2018.

KORTENKAMP, D.; BONASSO, R. P.; MURPHY, R. Artificial intelligence and mobile robots: case studies of successful robot systems. Massachusetts, The MIT Press, 1998.

LEWIS, F. L.; DAWSON, D. M.; ABDALLAH, C. T. Robot manipulator control - theory and practice. New York, Marcel Dekker Inc., 2004.

MALMONGE, S. M. et al. Uma proposta de laboratório de ensino interdisciplinar na UFABC e a inserção da mecânica aplicada no ensino médio. Anais... Congresso Brasileiro de Educação em Engenharia (COBENGE), Gramado, RS, 2013.
MTAB. ARISTO robot. Disponível em: $<$ https://mtabindia.com/robotics/aristorob otics.htm>. Acesso em: 13 jul. 2019.

NEHMZOW, U. Mobile robotics - a practical introduction. New York, Springer, 2003.

OGATA, K. Modern control engineering. New York, Prentice Hall, 2011.

PEREIRA, V. G. et al. Robô móvel com controle embarcado em um microcontrolador como ferramenta de ensino. Anais... Congresso Brasileiro de Educação em Engenharia (COBENGE), Gramado, RS, 2013.

RIBEIRO, P. C.; MARTINS, C. B.; BERNARDINI, F. C. A robótica como ferramenta de apoio ao ensino de disciplinas de programação em cursos de computação e engenharia. Anais... Simpósio Brasileiro de Informática na Educação (SBIE), Aracaju, SE, 2011.

SIEGWART, R.; NOURBAKHSH, I. R. Introduction to autonomous mobile robots. Massachusetts, The MIT press, 2004.

SPONG, M. W.; HUTCHINSON, S.; VIDYASAGAR, M. Robot modeling and control. New York, John Wiley and Sons Inc., 2005.

STANKOVSKI, Stevan et al. Using a didactic manipulator in mechatronics and industrial engineering courses. IEEE transactions on education, v. 53, n. 4, November, 2010. 


\section{DADOS BIOGRÁFICOS DO AUTOR}

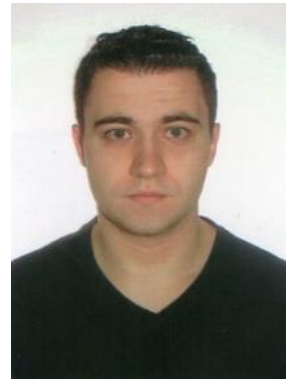

Caio Igor Gonçalves Chinelato - Bacharel em Ciência e Tecnologia em 2009 e no curso de Engenharia de Instrumentação, Automação e Robótica em 2011, ambos obtidos pela Universidade Federal do ABC (UFABC). Mestrado em Engenharia Mecânica obtido pela UFABC em 2014, na área de robótica e sistemas de controle. Desde 2014 atua como docente no Instituto Federal de São Paulo (IFSP) - campus São Paulo com enfoque nos cursos Engenharia de Controle e Automação, Engenharia Eletrônica e Tecnologia em Automação Industrial. Suas principais linhas de pesquisa são: robótica, sistemas de controle, mecatrônica e automação. 